\title{
A importância do planejamento gestacional para diferentes gerações de mulheres
}

The importance of gestational planning for different generations of women

La importancia de la planificación gestacional para diferentes generaciones de mujeres

\section{Amanda Paulina Pinheiro de Medeiros}

Universidade Federal do Rio Grande do Norte, Brasil

E-mail: a.medeirosamanda@gmail.com

Carla Maria Santana

Universidade Federal do Rio Grande do Norte, Brasil

E-mail: carlamariasantana96@gmail.com

Danielle Oliveira Ferreira

Universidade Federal do Rio Grande do Norte, Brasil

E-mail: admdannioliveira@hotmail.com

Kécia Cristina Ribeiro

Universidade Federal do Rio Grande do Norte, Brasil

E-mail: kecia.pesquisa@gmail.com

Max Leandro de Araújo Brito

ORCID: https://orcid.org/0000-0003-2827-9886

Universidade Federal do Rio Grande do Norte, Brasil

E-mail: maxlabrito@gmail.com

Recebido: 05/10/2018 | Revisado: 18/10/2018 | Aceito: 29/10/2018 | Publicado: 01/11/2018

\section{Resumo}

O presente estudo tem por objetivo compreender a importância do planejamento gestacional na ótica de diferentes gerações de mulheres. O presente artigo é qualitativo realizado com mães de diferentes idades, faixa de rendas, classes sociais e instituições familiares. Como resultados o estudo revela que a falta de planejamento do período pós parto dificulta os primeiros meses da vida do recém-nascido e da mãe. Por fim, o estudo infere que o planejamento gestacional é importante para os períodos que antecedem à gestação, o gestacional e o pós-gestação, no tocante à qualidade de vida da mulher e do bebê, enquanto indivíduos mais envolvidos diretamente, bem como no que diz respeito às mudanças no ambiente familiar para os demais, como o pai, os avós, outros filhos.

Palavras-chave: mãe; recém-nascido; parto; família. 


\begin{abstract}
The present study aims to understand the importance of gestational planning from the perspective of different generations of women. The article is qualitative, being carried out with mothers of different ages, range of income, social classes and family compositions. As a result the study reveals that the lack of planning of the post partum period hinders the first months of the life of the newborn and the mother. Finally, the study infers that gestational planning is important for the periods before gestation, gestation and post gestation, regarding the quality of life of the woman and the baby, as individuals more directly involved, as well as in what refers to changes in the family environment for others, such as the father, the grandparents, other children.
\end{abstract}

Keywords: mother; newborn; childbirth; family.

\title{
Resumen
}

El presente estudio tiene por objetivo comprender la importancia de la planificación gestacional en la óptica de diferentes generaciones de mujeres. El presente artículo es cualitativo realizado con madres de diferentes edades, rango de rentas, clases sociales e instituciones familiares. Como resultados el estudio revela que la falta de planificación del período post parto dificulta los primeros meses de la vida del recién nacido y de la madre. Por último, el estudio infiere que la planificación gestacional es importante para los períodos que preceden a la gestación, el gestacional y el post-gestación, en cuanto a la calidad de vida de la mujer y del bebé, como individuos más involucrados directamente, así como en lo que se refiere a los cambios en el ambiente familiar para los demás, como el padre, los abuelos, otros hijos.

Palabras clave: madre; recién nacido; entrega; familia.

\section{Introdução}

A sociedade brasileira se mostrou ao longo dos tempos uma sociedade pró-natalista, no entanto o Estado nunca formulou políticas populacionais, embora tenha em sua Constituição de 1937, mais precisamente em seu art. 124, abordava que "A família, constituída pelo casamento indissolúvel, está sob a proteção especial do Estado. As famílias 
numerosas serão atribuídas compensações na proporção de seus encargos". Naquele período, existia incentivos ao casamento e à reprodução, evidenciado por meio de uma legislação que proibia o uso de contraceptivo e o aborto, sendo elas: o Decreto Federal n. 20.291, de 1932 que estabelecia "É vedado ao médico dar-se à prática que tenha por fim impedir a concepção ou interromper a gestação"; e a Lei das Contravenções Penais, de 1941 que proibia em seu artigo 20: "anunciar processo, substância ou objeto destinado a provocar o aborto ou evitar a gravidez".

No tocante à contribuição do tema no dia - a - dia, há duas considerações centrais, quais sejam em primeiro lugar melhorar o acompanhamento da gestante durante as atividades no pré natal e, em segundo lugar, esclarece o papel da família e do ambiente no qual a grávida está inserida.

Tendo em vista o contexto apresentado acima o estudo tem por objetivo compreender a importância do planejamento gestacional na ótica de diferentes gerações de mulheres. Desse modo, o artigo apresenta as influências dos aspectos relacionados a parto humanizado, prénatal e planejamento familiar, universo ao qual o planejamento da gestação pertence. Em seguida, são expostos metodologia, resultados e referências, respectivamente.

\section{Parto Humanizado}

Desde o fim da década de 1990 têm-se observado um crescente aumento nos partos de tipo cesariana, em relação aos partos normais, nos municípios brasileiros, chegando a extrapolar o limite considerado aceitável pela Organização Mundial de Saúde (OMS). Diante disso, o Ministério da Saúde estabeleceu um teto de gastos hospitalares destinados às cesáreas, medida que nos possibilitou ficar aquém dos também altos índices de partos cesáreas existente no Chile. Os motores desse fato giram, basicamente, em torno de dois pontos chaves, quais sejam: primeiro, o pensamento comum das mulheres que superestimam os benefícios da cesárea e subestimam seus riscos e; secundariamente, a soma dos erros profissionais que se repetem em virtude dos regimes de plantões, por vezes estressantes, à notória, mas não exclusiva, tendência de judicialização da saúde (COSTA, 2018).

Nesse mesmo contexto, surgiu o conceito de violência obstétrica, fruto tanto de denúncias de desrespeito no parto feitas pelo Ministério Público, quanto de discussões entre os profissionais da saúde acerca de intervenções desnecessárias praticadas sem consentimento durante o parto, ensejando uma polarização entre profissionais da saúde e mulheres, estas, mais especificamente, declarando-se sem voz em um momento de tanta vulnerabilidade (OLIVEIRA; PENNA, 2017). 
$\mathrm{O}$ conceito aludido tornou-se ainda mais válido à medida em que algumas parteiras começaram a expor seus pontos de vista que, nada obstante suas posições de profissionais da saúde, endossaram os relatos das mulheres. Elas também reconhecem a polarização e a dificuldade que ela impõe, vez que há médicos que procedem de maneira rude com as parturientes ignorando deliberadamente as complicações físicas e psicológicas pelas quais estas passam, bem como sentem que os desrespeitos extendem-se às equipes. No entanto, o dever das parteiras é obedecer às orientações dos médicos e, ainda que sejam mais empáticas e discordem da postura, precisam colocar à parte suas considerações, silenciando-as (OLIVEIRA; PENNA, 2017).

Ocorre que no parto a protagonista deve ser a mulher e o papel da equipe obstétrica é cuidar para que tudo aconteça com qualidade para ela e o bebê (ORTOLANI; IGNATTI, 2018). Em relação a este, a atenção inicia-se como uma extensão da atenção necessária à mãe em trabalho parto, tendo em vista que asfixia perinatal pode causar graves sequelas à criança ou, até mesmo, levá-la a óbito. A presença da enfermeira obstétrica tornou-se crucial, entre outras coisas, por essa razão, já que orienta a parturiente sobre os procedimentos não invasivos e assistem-nas quando optam por uma posição verticalizada (VARGENS; SILVA; PROGIANTI, 2017).

A ascensão da humanização do parto visou tratar com sutileza a violência obstétrica. Esta, por sua vez, ganhou tanta atenção negativa que passou a ser considerado um termo forte, evitado, inclusive, pela Organização Mundial da Saúde (OMS) que se refere a ele como tratamento hostil, agressivo ou desrespeitoso, dadas as lacunas que permanecem no sentido global da expressão, ainda que as repreensões sejam fatos cotidianos nas maternidades (OLIVEIRA; PENNA, 2017).

Como o modelo tradicional ainda é o principal, o modelo humanizado permanece em seu processo de implantação, razão pela qual, não raramente, encontram-se nos hospitais e maternidades ambos tipos de parto sendo oferecidos alternada ou concomitantemente. Novamente, a figura da enfermeira obstétrica se destaca, pois, por estar mais próxima da mulher, suas reflexões são importantes para aliar o conhecimento profissional aos cuidados humanizados no ambiente hospitalar (VARGENS; SILVA; PROGIANTI, 2017).

A intenção principal dos estudiosos do tema é chamar atenção para a problemática supradescrita para que haja maior socialização do tema e surjam discussões governamentais e profissionais voltadas para ela. Essa intenção é sustentada pelo fato de que há muitos fatores a se considerar pois, apesar da notória dubiedade na conduta dos médicos, mesmo as enfermeiras que entendem as mães, mas silenciam e as próprias vítimas que consentem e até 
justificam as agressões dos médicos, contribuem para a perpetuação da violência obstétrica (OLIVEIRA; PENNA, 2017).

\section{Aspectos Psicológicos}

A gravidez e a maternidade são eventos de grande importância na vida dos casais, mas podem gerar alterações físicas, mas comumente os transtornos mentais e comportamentais. (ANDRADE et al, 2017)

Pelo menos 450 milhões de pessoas sofrem de algum tipo de Transtorno Mental (TM). Os Transtornos Mentais trazem como consequência incapacidade e morte em todo o mundo. As mulheres são mais suscetíveis a este problema do que os homens, principalmente quando se trata da ansiedade, depressão e doenças mentais. (COSTA et al, 2018)

O baixo apoio social e familiar; conflito e insatisfação conjugal; não ter apoio de seu parceiro; falta de apoio social no puerpério; exposição à violência por parceiro íntimo no ciclo gravídico puerperal e conflito familiar são fatores de risco para a mulher gestante que pode vir a desenvolver doenças psicomentais. (ARRAIS; ARAÚJO, 2017)

Esse tipo de doença pode trazer desfechos negativos à mulher e ao feto, uma vez que, quando não há preocupação em tratar o problema, aumentam os riscos das grávidas em adotarem maus hábitos como o de tabagismo, alcoolismo e até mesmo drogas. Como consequência para a nova rotina da mãe, poderá ocorrer redução do autocuidado, como diminuir a quantidade e a qualidade alimentar e não aderir ao acompanhamento pré-natal, causando desnutrição, morbimortalidade neonatal, prematuridade, restrição do crescimento intrauterino e mortalidade materna. (COSTA et al, 2018)

Dentre as doenças mentais que podem afetar a mulher após o período puerpério está a tristeza puerperal, também conhecida como Maternity Blues ou Postpartum Blues, caracterizada pelo choro, irritabilidade e humor deprimido. Esse problema geralmente aparece entre o $3^{\circ}$ e $10^{\circ}$ dia após o parto e pode evoluir para um transtorno severo. (ANDRADE et al, 2017)

Estudos apontam que ter um acompanhamento adequado no programa pré-natal, com base uma abordagem psicológica, e o relacionamento saudável da gestante com sua própria mãe, são fatores que podem contribuir para a prevenção da depressão pós-parto. (ARRAIS; ARAÚJO, 2017)

A identificação de possíveis transtornos mentais pode ocorrer através de avaliações clínicas e o cuidado pré-natal, podendo ser, este último, o único contato que a mulher pode ter durante a gestação. Dessa forma, é indispensável todo o cuidado e acompanhamento da saúde da gestante neste período, pois contribuirá com a qualidade na assistência às famílias (COSTA et al, 2018) 
Também são fatores preventivos a percepção de suporte social durante a gravidez, apoio social no puerpério e as relações sociais positivas. (ARRAIS; ARAÚJO, 2017)

\section{Planejamento Familiar}

Planejamento familiar serve de orientação às famílias, respeitando suas liberdades no que tange ao controle de fertilidade, visto que, nada obstante às previsões legais da Carta Magna de 1988 e da própria Lei n ${ }^{\circ}$ 9.263/96 que tratam formalmente do tema, não é meio para que o Estado pratique controle demográfico. (Fernandes, 2003; Pereira, 1978; apud ARPINI; MOZZAQUATRO, 2017).

No mesmo sentido, vale salientar que partindo dos princípios dos direito humanos, a constituição familiar não necessariamente tem que seguir padrões de forma, momento, meios e afins para serem reconhecidas social e legalmente, de maneira que as famílias devem ter suas origens e autonomias respeitadas, livres de imposições de modelos (GALLO; GRACINDO, 2016).

Com o fito de assegurar o exercício dos direitos previstos para o tema podem servir de meio tanto diretrizes da saúde quanto da educação. Nesse sentido, sabe-se que em nosso país as primeiras predominam, desde 1984, por intermédio da Assistência da Saúde da Mulher e, há cerca de dez anos, também passou a constar da Política de Atenção à Saúde do Homem, a qual apresenta a paternidade tanto como um direito quanto como um dever, estimulando-o a participar também do planejamento familiar. Complementarmente, a aliança entre os programas de saúde acima descritos tem relevância para ensejar o esclarecimento no que diz respeito à contracepção, cuja responsabilidade ainda é majoritariamente atribuída à mulher, ainda que hoje as obrigações parentais sejam mais divididas entre alguns casais (ARPINI; MOZZAQUATRO, 2017).

Concorrendo para a gama de elementos que contribuem para ensejar melhorias no âmbito do planejamento familiar estão, consoante o segundo parágrafo deste tópico, as ferramentas jurídicas. Nesse rumo, o Conselho Nacional de Justiça (CNJ) avançou com edição do Provimento $n^{\circ} 52$, de março de 2016, congênere a provimentos preexistentes em alguns poucos estados, regulamentando nacionalmente a emissão de certidão de nascimento para filhos gerados por técnicas de reprodução assistida tanto de casais heteroafetivos, quanto homoafetivos, bem como corroborando com a constitucionalidade das diversas formas previstas de família (GALLO; GRACINDO, 2016). 


\section{Metodologia}

O presente artigo é qualitativo. A amostragem foi por conveniência. " a amostragem por conveniência refere-se à seleção daqueles casos mais acessíveis sob determinadas condições. Isso pode acontecer simplesmente em função de se reduzir o esforço. No entanto de tempos em tempos, esse critério possivelmente represente o único caminho para realizar-se uma avaliação com recursos limitados de tempo e de pessoa”. (FLICK,2009).

Foram escolhidas seis entrevistadas. A primeira, Sujeito A de 50 anos que engravidou aos 28 anos e ainda grávida se separou do marido, reatando 19 anos depois, após a única filha já ter saído de casa. A segunda, Sujeito B, 44 anos, engravidou aos 41 e é atualmente casada. A terceira, Sujeito C de 22 anos, engravidando aos 19 anos, em união estável. A quarta, Sujeito D, 33 anos, com gestação aos 24 anos, solteira. Quinta, Sujeito E, 37 anos, engravidou aos 22 anos, em união estável e a sexta, Sujeito F, 59 anos, engravidou aos 39 anos, em união estável.

A coleta de dados ocorreu por meio de entrevista estruturada com quatro perguntas. A aplicação das entrevistas ocorreu através de aplicativo de mensagem instantânea e pessoalmente.

O método de análise utilizado foi a análise de conteúdo por meio da interpretação das falas dos sujeitos.

\section{Resultados}

A primeira pergunta realizada às respondentes era como foi o planejamento da gestação. Em relação à essa pergunta, Sujeito A, respondeu que "Havia dentro de mim um grande desejo de ser mãe, um sonho que eu queria tornar realidade desde que me casei, aos 21 anos. Mas infelizmente eu tinha distúrbios hormonais que não me permitiam ovular e como conseqüência eu também não conseguia engravidar. Então foram sete anos tratando deste problema, sete anos sonhando com o dia em que eu seria mãe, e finalmente aos 28 anos eu pude ter essa alegria. Fiquei grávida.”

Para Sujeito B, "Devido o fato de eu ter me casado aos 39 anos, meu marido e eu optamos por não esperar muito para termos o nosso primeiro filho. Poderia haver complicações devido a minha idade, ou coisa semelhante. Antes de 'liberar' para engravidar, eu fiz alguns exames para saber como estava a minha saúde de modo geral e mais especificamente a saúde do útero, ovários, etc. Como eu tomei anticoncepcionais por muitos 
anos, acredito que desde meus 16 anos, eu descobri que tinha um ovário atrofiado. Logo fiquei 'louca' achando que isso me impossibilitaria de engravidar, mas o médico falou que eu poderia sim, afinal sempre tive minha menstruação regulada e, fora este, não havia outros problemas. Segui as orientações médicas com um breve tratamento preventivo para garantir uma gravidez saudável e fui medicada com algumas suplementações como o ácido fólico e ferro, que tomei durante 6 meses. Quando o médico disse que estava tudo certo e que eu já podia 'liberar', não deu outra. Engravidei de primeira."

Para o Sujeito C, "De certa forma nada foi planejado, eu queria muito ser mãe, claro, mas os planos são do criador. Ele soube nos dar no momento certo o maior presente que alguém pode possuir". Para o Sujeito D, "Não foi planejado". Para o Sujeito E, "a minha primeira gestação não foi planejada, mas recebi bem a notícia da gravidez.”. Para o Sujeito F, "Não foi planejada".

Os sujeitos A e B planejaram a gestação e precisaram de um tratamento adequado antes de engravidar. Sujeito A descobriu que não era fértil após inúmeras tentativas de engravidar, enquanto Sujeito B descobriu algumas irregularidades em seu corpo através de um exame de prevenção que fazia parte do seu planejamento gestacional. Dessa forma, foi detectada a necessidade de ambas em preparar o corpo antes de abrigar o feto.

Já os sujeitos C e D, não planejaram suas gestações, no entanto reagiram positivamente diante do fato ocorrido. Enquanto para os sujeitos E e F, receberam bem a notícia de suas gestações mesmo não sendo planejadas.

Há uma grande necessidade da mulher se preparar antes de engravidar, principalmente no que diz respeito a sua saúde. Exames pré-gestacionais são fundamentais para descobrir qualquer alteração que o corpo possa ter e acabar prejudicando ou impedindo ou período seguinte, a gestação.

Em seguida foi perguntado que tipo de assistência médica foi utilizada durante a gravidez e parto.

Sujeito A afirma: "Eu fiz todo meu tratamento antes de engravidar pelo meu plano de saúde, na época, ainda casada, eu tinha esses benefícios devido o emprego do meu marido. Depois que engravidei, me divorciei, e o meu acompanhamento médico foi feito no setor público mesmo. Na época a saúde pública funcionava muito bem, obrigada. Nunca me foi negada assistência, tive todos os meus direitos exercidos.

Meu parto foi feito na maternidade aqui de Currais Novos mesmo, tudo ocorreu bem. Naquele tempo não faltavam materiais para atender a população." 
Sujeito B responde: "Fiz todo meu acompanhamento pelo meu plano de saúde da UNIMED, onde fui acompanhada por um médico especialista em gravidez de risco. Não que a minha fosse, mas devido a minha idade e o fato de as pessoas ficarem toda hora colocando na cabeça da gente que engravidar depois dos 35 é arriscado, eu fiz essa escolha para garantir que qualquer eventual problema pudesse ser rapidamente diagnosticado e tratado, evitando colocar a minha gravidez em risco. Fiquei hipertensa durante a gravidez, mas tudo foi mantido sob controle. Meu parto também foi realizado por ele."

O Sujeito C diz "Fiz meu acompanhamento de pré-natal no PSF, e dei a luz em uma maternidade pública. Tudo custeado pelo SUS".

Já o Sujeito D afirma “A assistência na minha gestação foi através do pré-natal pelo SUS e parto realizado na Maternidade Ananilia Regina, da rede pública, situado na cidade Currais Novos, RN".

O sujeito E diz "A minha assistência ao descobrir foi ir para o postinho fazer o cadastro e todo mês ia para consulta até os nove meses"

Enquanto para o Sujeito F "Toda assistência necessária com obstetra, pediatra anestesista. Pré natal durante o período gestacional"

Sujeito A, C, D, E e F tiveram seus acompanhamentos pré-natais na saúde pública em uma época que, para os mesmos, esse departamento não se encontrava deficiente. Já Sujeito B teve seu filho em tempos de Brasil passando por inúmeras dificuldades. E para ter um atendimento especializado que atendesse às suas necessidades, foi necessário contratar um plano de saúde particular para garantir que sua gravidez fosse bem sucedida.

O planejamento da gravidez é importante para que a mulher não seja pega de surpresa em alguns aspectos, como por exemplo, o financeiro. Pode ocorrer de que ela ou o bebê precise de um tratamento específico, tenha alguma complicação durante ou após a gravidez e que a saúde pública não tenha estrutura para dar suporte. Sendo assim, ela precisará estar preparada para arcar com os custos ou seguirá colocando sua vida e/ou a do bebê em risco.

Perguntou-se também qual tipo de parto foi escolhido, o por quê e qual realmente foi utilizado.

Sujeito A respondeu da seguinte forma: "Na verdade eu não escolhi qual o tipo de parto eu queria. Estava esperando ter normal, que para mim era a forma "natural" de ser ter um filho, mas como não tive 'passagem', fui obrigada a aceitar a realização do parto cesárea. É bem complicado, você acaba se tornando dependente de alguém durante a recuperação para cuidar de você e do seu filho nesse período. Ainda bem que eu tinha a minha mãe." 
Sujeito B alegou: "Meu parto eu queria muito que fosse normal, eu tinha um forte desejo de sentir a dor de ser mãe, as contrações, a ansiedade, o medo, eu queria passar por cada fase. Sei que sou forte suficiente para isso. Estava preparada para cada fase. Mas além de ele não ter dado sinal nenhum de que era hora, infelizmente não houve dilatação para passar meu filho que pesou 4,960kg e mediu $59 \mathrm{~cm}$. Então fizemos cesárea, eu já estava nos '10 dias depois' esperando sentir alguma dor de parto, mas não tive."

O Sujeito C afirmou "Eu sempre quis que meu bebê viesse ao mundo por um parto normal, queria sentir o que no meu ponto de vista, é ser mãe. E desde o início da minha gestação tinha tudo pra ser um parto normal, e foi”.

O Sujeito D diz "Tive um parto cesariano, devido a uma complicação de saúde não foi possível ser normal".

Sujeito E fala que "Meu parto foi cesária por que não tinha nenhuma contração".

O Sujeito F afirma "Parto cesariana. Porque eu não tinha condições de parir normal ir desproporção".

O parto favorito entre as entrevistadas foi o parto normal, considerado como algo natural e saudável para a mulher. Mas a maioria acabaram se submetendo ao parto cesárea.

Sujeito A e B apresentaram dificuldades para cuidarem do bebê e de si mesmas durante a recuperação, tendo sido ainda mais complicado para Sujeito $B$, que não teve apoio familiar e adquiriu depressão pós parto.

O planejamento gestacional é importante até mesmo quando se trata do apoio familiar. A menos que você escolha o parto cesárea por opção você não sabe o tipo de parto que realmente irá ser realizado, o que gera a necessidade de se programar para as duas opções, podendo contar ou não com o apoio de parentes ou de terceiros, evitando que a mulher passe por transtornos causados pelo despreparo que pode afetar sua saúde física e mental.

Por fim, as participantes responderam o que fariam diferente na próxima gestação.

Sujeito A: "Bem, eu não tenho mais idade para uma próxima gestação. Estou esperando meus futuros netos [risos]. A única coisa que penso é que eu gostaria de ter tido mais filhos."

Sujeito B: "Contraria uma pessoa para me auxiliar com o bebê, pois a minha experiência de mãe de primeira viagem foi bem complicada porque eu tive depressão pós parto. Meu desespero em não saber pegar, não saber o que fazer, não saber dar um banho, não saber nada, não ter quem me ajudasse porque minha mãe já era de idade e doente, não conseguir dormir a noite com a criança chorando e eu sem saber o que fazer, meu marido também não sabia como me ajudar, ficava ausente o dia todo cuidando do nosso negócio. 
Minha vontade era de sair correndo no meio da rua para fugir daquela situação. Hoje eu já tenho alguém que cuida do meu filho, mas eu gostaria de contratar mais uma pessoa pra me ajudar com o novo bebê só durante o período de resguarde, para eu poder ter uma boa recuperação. E depois disso a babá me ajudaria com os dois."

Para o sujeito C, "Essa não sei responder, de verdade".

O Sujeito D afirma, "Seria algo planejado, mas não tenho planos de ser mãe novamente".

Sujeito E: "Na minha segunda gestação foi a mesma coisa não foi planejado mas já que aconteceu recebemos com todo carinho, fiz os mesmos procedimentos, no finalzinho da gestação fiz um acompanhamento com a assistente social para a gente fazer a ligação quase que não conseguia mas elas me deram a autorização só que na hora que fui ter o bebê eu entrei em trabalho de parto e ele foi normal, ai acabei que não liguei, e o mais se eu engravidasse não faria nada diferente não, fazia o mesmo, e também não seria planejado também".

Já o sujeito $\mathrm{F}$ afirma que, "teria um parto normal por ser uma recuperação mais rápida".

É possível identificar na resposta do Sujeito A, a satisfação que foi sua gravidez. Por outro lado, Sujeito B demonstra que teve um período de recuperação do parto cesárea cheio de complicações. Se preocupar com a chegada e o conforto do bebê é algo que deve sim acontecer, mas não pode-se esquecer do conforto e saúde da mãe. Se ela não está bem, o bebê não estará bem.

Sujeito C não conseguiu responder o questionamento e o Sujeito D não tem planos de ser mãe novamente. Sujeito E já teve uma outra gestação e se futuramente ocorrer uma nova gestação não faria nada diferente, já o Sujeito $F$ não tem planos futuros para uma nova gestação.

O presente trabalho tem por objetivo refletir sobre o planejamento gestacional de mulheres com idades entre 19 e 59 anos. A metodologia utilizada é qualitativa, consistindo em um estudo de caso com seis mulheres, com idades de 19, 22, 24, 39, 44 e 50 quando ocorreram suas gestações entre os anos de 1959 a 2015. Dentre os resultados apresentados no estudo estão que a maioria das entrevistadas não planejaram a gravidez, no entanto reagiram de maneira positiva diante da nova fase. A assistência médica recebida pelas entrevistadas foi por meio do Sistema Único de Saúde (SUS) com a realização de pré-natais. Os relatos em relação aos partos dessas mães divergem quanto ao tipo de parto que foi escolhido, pois parte delas queriam que seu filho viesse ao mundo por meio de parto normal e assim aconteceu, 
enquanto outras mães, devido à complicações no seu estado de saúde, teve que dar à luz ao seu filho por meio de uma cesariana. Quanto ao planejamento de uma próxima gravidez, as mães entrevistadas afirmaram o desejo de haver um planejamento, contudo no momento não planejam outra gestação. Por fim o estudo conclui que o planejamento gestacional é importante para as mulheres que desejam ter filhos, proporcionando uma gestação tranquila e principalmente diante das responsabilidades que serão assumidas após o nascimento.

\section{Conclusão}

Os dados da pesquisa revelam que o planejamento gestacional é importante para os períodos que antecedem à gestação, o gestacional e o pós-gestação, no tocante à qualidade de vida da mulher e do bebê, enquanto indivíduos mais envolvidos diretamente, bem como no que diz respeito às mudanças no ambiente familiar para os demais, como o pai, os avós, outros filhos, entre outros. Exemplo disso foi o caso da senhora Sujeito B, cuja gravidez foi parcialmente planejada, considerando apenas os aspectos físicos da pré-gestação e da gestação em si, tendo desconsiderado possíveis implicações, tais como parto cesárea, para o qual a estrutura familiar não se adequava.

O presente estudo teve como limitações a dificuldade de definição da amostra a ser questionada, tendo em vista o curto espaço de tempo para elaborar o roteiro de pesquisa e interpretar as respostas colhidas. $\mathrm{O}$ fato da maioria dos membros do grupo nunca terem passado pela experiência da maternidade, vez que apenas uma entre as quatro integrantes é mãe, também tolheu os horizontes da relevância dos resultados encontrados.

Como sugestão para futuras abordagens do tema, as autoras indicam mais atenção às questões de estrutura familiar, planejamento financeiro global (para os três períodos iniciais da maternidade) e aspectos psicológicos da mulher também para os três períodos.

\section{Referências}

ARPINI, D. M., MOZZAQUATRO, C. O. Planejamento familiar e papéis parentais: o tradicional, a mudança e os novos desafios. Psicologia: Ciência e Profissão. Rio Grande do Sul, v. 37, no 4, p. 923-938, out/dez 2017; 
COSTA, S. P. et al. Transtornos mentais na gravidez e condições do recém-nascido: estudo longitudinal com gestantes assistidas na atenção básica. Ciênc. saúde coletiva. Rio de Janeiro, vol. 23, $\mathrm{n}^{\circ} 3$, mar. 2018.

ARRAIS, A. R., ARAÚJO, T. C. C. F. Depressão pós-parto: uma revisão sobre fatores de risco e de proteção. Psic., Saúde \& Doenças. Lisboa, vol.18, nº3, dez. 2017.

ANDRADE, M. et al. Tristeza materna em puérperas e fatores associados. Revista Portuguesa de Enfermagem de Saúde Mental. Porto, nº18, dez. 2017.

GALLO, J. H. S., GRACINDO, G. C. L. Reprodução assistida, direito de todos. E o registro do filho, como proceder? Rev. Bioét. V. 24, n. 2, p. 250-259, 2016;

OLIVEIRA, V. J., PENNA, C. M. M. Discussing obstetric violence through the voices of women and health professionals. Texto contexto - enferm., Florianópolis, v. 26, n. 2, e06500015, 2017.

ORTOLANI, Solange; IGNATTI, Carmencita. Resultados da abordagem do Diabetes Mellitus Gestacional no Centro de Especialidades em Saúde da Mulher e da Criança de Itanhaém-SP. Research, Society and Development, v. 7, n. 1, e1171122, 2018

VARGENS, Octavio Muniz da Costa; SILVA, Alexandra Celento Vasconcellos da; PROGIANTI, Márcia. Contribuição de enfermeiras obstétricas para consolidação do parto humanizado em maternidades no Rio de Janeiro-Brasil. Esc. Anna Nery, Rio de Janeiro, v. 21, n. 1, e20170015, 2017. 